\title{
Thirteen years (2000-2012) at the helm of information technology and management: a retrospective
}

\author{
Varghese Jacob · Hasan Pirkul
}

Published online: 15 December 2012

(c) Springer Science+Business Media New York 2012

The first issue of Information Technology and Management was published by Baltzer Science Publishers in November 1999. Our goal was to make the journal a broad spectrum information technology journal. This goal was laid out in the introduction to the first issue (Pirkul and Jacob [1]) in which we stated, "..it is important to have a journal where the readers will be exposed not only to different technologies but also to their impact on information system design, functionality, operations and management. It should be emphasized that information systems include not only machines but also humans; therefore, the journal will be an outlet of studies dealing with man/machine interface, human factors and organizational issues. Furthermore, both managerial and strategic issues arising from and dealing with management of information technology are included in the domain of coverage." Over the years we have worked to ensure this broad spectrum appeal continued to hold both with a mix of special issues guest edited by experts in specific domains as well as regular issues containing papers that were submitted and went through a rigorous review process.

The special issues covered a broad array of topics, the first volume had three special issues. The first issue guest edited by Jacob and Whinston [2] focused on Electronic commerce this was followed by a special issue with selected papers from the 1998 Workshop on Information Technology and Systems focusing on IT in support of business process guest edited by March and Bubenko [3] the conference co-chairs. The first volume was rounded off by Holsapple [3] who guest edited a special issue on

\footnotetext{
V. Jacob $(\bowtie) \cdot$ H. Pirkul

Naveen Jindal School of Management, The University of Texas at Dallas, Richardson, TX 75080-3021, USA

e-mail:vjacob@utdallas.edu
}

technology in business education. Since then the journal has generated 30 special issues including the current issue, on diverse topics, with several of these issues showcasing selected papers from various conferences.

The first regular issue appeared as the first issue of volume 2 in year 2001. The breadth in scope of the journal was established right at the beginning with each of the five articles addressing a different topic with a different methodology. The first article by Agarwal et al. [4] looked at a classification decision context using Neural Networks. The second article by Orman [5] looked at the database audit problem and strategies for performing it efficiently and effectively. The third paper by Robey et al. [6] proposes a component based paradigm for software development and uses a social analysis framework to analyze the approach with traditional approaches. The next paper in the issue by De et al. [7], performs an empirical investigation of the different approaches to object oriented database querying. They conducted an experiment to analyze a graphical object oriented database schema with a textual one. The final paper in that issue by Benamati and Lederer [8] uses the results from a survey they conducted to understand the coping mechanisms IT managers use to handle rapidly changing IT. Since then the journal has published twenty regular issues and we have attempted to maintain this diversity.

At this juncture the journal has a strong pipeline of special issues and regular papers, therefore, we felt it is time to hand over the reins of the journal to the younger generation. We are very pleased that Raymond Patterson and Erik Rolland have agreed to step in as the new editors of the journal. We believe they have the right mind set and the energy to take the journal to the next level.

As we hand over the reins to Ray and Erik we wanted to highlight the current status of the journal, the journal for 
2011 got submissions from 31 different countries, over 7,000 institutions worldwide have online exposure to the journal via online deals made with the publisher. The acceptance rate for papers in the regular issue hovers around $12 \%$ and the journal has 23,344 downloads of full text articles for 2011 up from 19,653 in 2010. Clearly, the journal has a good established base but we believe these numbers can be strengthened and Erik and Ray will be able to take the journal further.

As with any undertaking of this magnitude there are a number of people we need to thank who have contributed to the journal in a myriad of ways to enable its success. We want to thank the authors who were willing to send their work to a new journal as well as the guest editors who were also willing to work with us and the authors to establish the journal as a high quality journal. We especially want to thank the advisory and editorial board members who have helped to establish the quality and standards for the journal. Finally, we would like to thank all the reviewers who have helped us in the review process. Last but not least we take this opportunity to thank the staff at Springer who are always prompt in their response to our requests and kept the production process humming along. We hope as the journal continues its journey forward all of you will continue to support the journal and the new Editors.

\section{References}

1. Pirkul H, Jacob V (2000) Editor's introduction to information technology and management. Inf Technol Manag $1(1,2)$

2. Jacob V, Whinston AB (2000) Electronic commerce. Inf Technol Manag 1 $(1,2)$

3. Holsapple CW (2000) Advances in technology for business education. Inf Technol Manag 1(4)

4. Agarwal A, Davis JT, Ward T (2001) Supporting ordinal four-state classification decisions using neural networks. Inf Technol Manag 2(1):5-26

5. Orman LV (2001) Database audit and control strategies. Inf Technol Manag 2(1):27-52

6. Robey D, Turk D, Welke R (2001) Traditional, iterative and component-based development: a social analysis of software development paradigms. Inf Technol Manag 2(1):53-70

7. De P, Sinha AP, Vessey I (2001) An empirical investigation of factors influencing object-based database querying. Inf Technol Manag 2(1):71-94

8. Benamati J, Lederer AL (2001) How IT organizations handle rapid IT change: five coping mechanisms. Inf Technol Manag 2(1):95-112 